\title{
A Public Preference for Home Care
}

A couple of years ago I wrote a column for this publication regarding public opinion on home care. That column reviewed the evolution of the public's views, concluding on an optimistic note that ...

"The home care debate is indeed maturing in Canadian public opinion. As problems in emergency and acute care settings are dealt with, the public will begin to demand increased attention to issues such as home care, not at the expense of hospitals, but as part of an integrated continuum of care that can improve the health outcomes of discharged hospital patients."

Since that time, the research that we have conducted for the Romanow Commission, through our Health Care in Canada annual series, and for Health Canada has confirmed the public's preferences for home care. And now home care has been placed squarely in the middle of the medicare reform debate, in part because Canadians express almost universal support for the federal government working with the provinces to fund a national home care program (92\%; including 57\% who strongly support.) Home care has risen steadily in recent years to become the most popular of potential new directions in medicare reform.

What are the dimensions of those preferences?

1. Comfort-Some $58 \%$ of Canadians tell us that they would prefer to recover from an illness or surgery in their home, compared to $36 \%$ who prefer to recover in a hospital (the balance have no opinion). These Canadians believe the home environment is more comforting, and tend to view professional home care services as equal or better than the quality of care received in hospitals.

2. Frugality - A clear majority of Canadians (63\%) view in-home medical care as less expensive than hospital care. This number ranges as high as 75\% among Canadians aged 45-64, who have high rates of contact with home care providers.

3. Quality - A majority (58\%) of Canadians view the quality of inhome medical care as equal to, or better than, the quality of hospital care. Just $27 \%$ perceive it to be worse, while some $15 \%$ say they just don't know.

And perhaps most important ...

4. Fairness - There is an overwhelming consensus in place in Canada that government should pay for home care as part of the universal healthcare plan. Fully $80 \%$ say the government should pay for in-home medical care, while just $11 \%$ say it should not. What is more, three-quarters (75\%) say that if government were to start helping to pay for in-home medical care, everybody who requires in-home medical care should be covered, regardless of whether they have private insurance. Just $22 \%$ think government should limit its role to the currently uninsured.

That being said, previous POLLARA studies have indicated that while Canadians believe that medicare should cover $100 \%$ of the people needing in-home medical care, they do not believe that medicare should necessarily cover $100 \%$ of the costs of different elements in the continuum of homecare.

On average, Canadians believe that coverage under medicare should cover the costs of:

- home visits by nurses to carry out medical procedures (81\%);

- pharmaceutical medications taken by chronic care patients at home (78\%);

- home visits by doctors (77\%);

- pharmaceutical medications taken by patients at home while recovering from short-term illnesses (70\%);

- visits for grooming and personal care (46\%).

Integrating home care into the medicare framework will be viewed by the public as an important and overdue innovation that fairness requires and comfort supports. Within reason, initial system costs can be sold as an investment that will reduce overall costs in the long run.

However, national home care will not be viewed by the public as a panacea for the concerns that still remain about timely access to quality care across acute settings, and shortages of human resources, diagnostics and surgical services. It is not the magic solution. The public will still be calling for leadership to bring forward the package of reforms that will satisfy the need for reform across the continuum of care.

Romanow and Kirby left the public optimistic about healthcare for the first time in several years, but created greater focus, expectations and momentum around healthcare than at any point since the Canada Health Act debate.

It is up to leadership to respond.

Don Guy is Senior Vice-President with POLLARA INC. For questions or comments about this column or similar matters, he can be contacted at 1-888-POLLARA or dguy@pollara.ca 